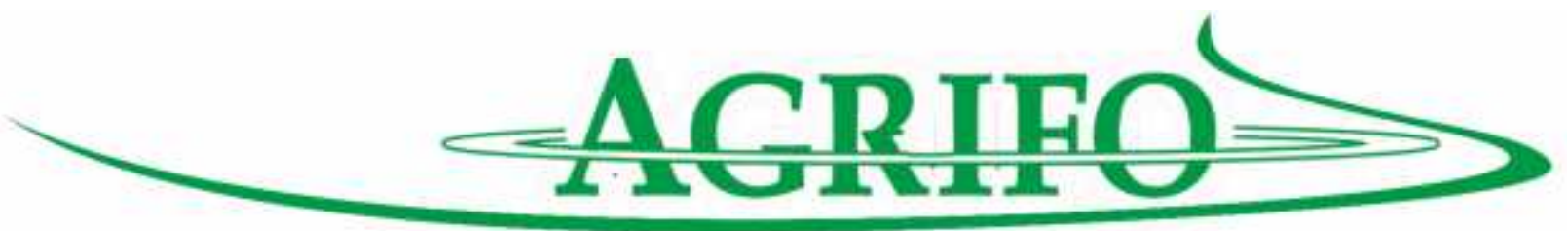

\title{
IDENTIFIKASI SALURAN PEMASARAN KOPI ARABIKA GAYO PADA CV. GAYO MANDIRI COFFEE KABUPATEN BENER MERIAH
}

\section{Riyandhi Praza ${ }^{1}$}

Email Author: riyandhi@unimal.ac.id

\begin{abstract}
The high selling price of coffee paid by consumers (importers) has not been felt by farmers. The development of Gayo Arabica Coffee marketing then emerged Cooperative and $\mathrm{CV}$ in Bener Meriah Regency in accommodating the production of farmers one of them. CV.Gayo Mandiri Coffee (GMC) located in District Bandar, Bener Meriah Regency. CV Gayo Mandiri Coffee is engaged in Gayo Arabica coffee marketing activities. This study aims to identify the marketing channel and the Gayo Arabica coffee production process. The research was conducted using qualitative descriptive method to analyze the primary and secondary data obtained. Primary data obtained through interviews and observations, while secondary data obtained through the literature associated with this research. Gayo Arabica coffee marketing in CV.Gayo Mandiri Coffee in marketing its products there are two channels, from collectors to producers to consumers, from producers directly to consumers and from producers to retailers as well as through intermediaries then to the hands of consumers. The most dominant channels contained in CV.Gayo Mandiri is channel I because this channel is the most effective and efficient in the marketing of green bean coffee Arabica Gayo.

Keywords: Identification, Arabica Coffee, Marketing channel
\end{abstract}

${ }^{1}$ Staff Pengajar Fakultas Pertanian Universitas Malikussaleh 


\section{PENDAHULUAN}

Kopi merupakan salah satu hasil komoditi perkebunan yang memiliki nilai ekonomis yang cukup tinggi diantara tanaman perkebunan yang lainnya dan berperan penting sebagai sumber devisa negara. Kopi tidak hanya berperan penting sebagai sumber devisa negara melainkan juga merupakan sebagai sumber penghasilan bagi tidak kurang dari satu setengah juta jiwa petani di indonesia (Rahardjo,2012). Keberhasilan agribisnis kopi membutuhkan dukungan semua pihak dalam peroses produksi kopi pengolahan dan pemasaran komoditas kopi. Upaya meningkatkan produktivitas dan mutu kopi terus dilakukan sehingga daya saing kopi di Indonesia dapat bersaing dipasar dunia (Rahardjo,2012).

Teknologi budidaya dan pengolahan kopi meliputi pemilihan bahan tanam kopi unggul, pemeliharaan,pemangkasan tanaman, dan pemberian penaung, pengendalian hama dan gulma, pemupukan yang seimbang, pemanenan dan pengolahan pasaca panen. Pengolahan kopi sangat berperan penting dalam menentukan kualitas dan cita rasa kopi (Rahardjo,2012). Kemajuan teknologi sangat mendukung pembangunan untuk mencapai kehidupan adil, makmur, dan merata bagi seluruh bangsa Indonesia dan hal ini tidak terlepas dari peran sektor ekonomi seperti perdagangan, industri, dan pertanian. Indonesia merupakan negara agraris, artinya bahwa pertanian memegang peranan penting dari keseluruhan pertanian nasional. hal ini dapat ditunjukan dari banyaknya produk atau tenaga kerja yang hidup atau bekerja pada sektor pertanian. pembangunan pertanian bertujuan untuk meningkatkan pendapatan dan taraf hidup petani, memperluas lapangan kerja dan kesempatan berusaha, menunjang pembangunan industri serta meningkatkan ekspor (Najiyati,2004).

Di Indonesia terdapat salah satu produsen utama kopi yaitu Provinsi Aceh. Dimana kopi Arabika Gayo merupakan komoditas utama Dikabupaten Aceh Tengah dan Bener Meriah. Sebagian besar (86\%) produksi kopi diekspor kepasar dunia . Sejak tahun 1992 petani Kopi Arabika Gayo telah terlibat dalam program sertifikasi produk yang berprinsip pada sistem pertanian berkelanjutan. Hingga saat ini beberapa sertifikasi produk kopi yang dimiliki antara lain Organic Sertified, Fairtrade Dan Raintforest (Najiyati.2004).

Proses produksi kopi di CV. Gayo Mandiri Coffee dimulai dari penjemuran gabah kopi Arabika Gayo dengan menggunakan cahaya matahari dengan waktu 1-2 hari tergantung dari baiknya penyinaran cahaya matahari. Adapun peroses selanjutnya gabah yang kering akan dimasukkan kedalam mesin penggilingan dan selanjutnya akan menghasilkan green bean (gabah hijau). Green bean tersebut akan dijemur kembali sampai kering namun tidak boleh terlalu kering karena nantinya akan mempengaruhi kualiatas dan cita rasa kopi dan dilakukan sortasi, selanjutnya dimasukkan kedalam karung untuk dipasarkan (ekspor) ke luar negeri dengan negara tujuan ekspor utama yaitu Amerika Serikat dan beberapa negara Asia lainya. 
Pemasaran hasil pertanian merupakan suatu kegiatan yang bertujuan untuk meningkatkan dan mengembangkan kegiatan pemasaran suatu produk, perusahaan harus mempertimbangkan saluran pemasaran yang dapat dipakai untuk menyalurkan produk dari produsen ke konsumen. Menurut Philip Kotler (1996) saluran pemasaran adalah serangkain organisasi yang saling tergantung dan terlibat dalam proses menjadikan suatu produk atau jasa siap untuk digunakan atau dikonsumsi. Sedangkan menurut Basu Swatha (1999) saluran pemasaran adalah saluran yang digunakan oleh produsen untuk menyalurkan barang tersebut dari produsen sampai ke konsumen atau pemakai industry.

Saluran pemasaran adalah serangkain organisasi yang saling tergantung dalam rangka proses penyaluran barang dari produsen kepada konsumen. Suatu barang dapat berpindah melalui beberapa tangan sejak dari produsen sampai kepada konsumen. Saluran pemasaran diperlukan untuk mengukur efisiensi pemasaran, menambah omset penjualan, memudahkan promosi, memudahkan negosiasi dan meningkatkan kontrak bisnis dengan partner dagang. Saluran pemasaran penting untuk dipelajari agar hasil produksi yang dipasarkan terjangkau secara ekonomi dengan tingkat saluran pemasaran yang singkat, sedangkan dengan semakin panjangnya saluran pemasaran harga yang diperoleh oleh konsumen akan lebih mahal.

Perantara pemasaran produk ini bermacam-macam dan biasanya bertingkat. Untuk tingkat pertama biasanya di tempati perwakilan wilayah yang biasnya perusahaan sendiri menanganinya. Kemudian ada agen tunggal yang mencakup daerah pemasaran lebih kecil. Perlu diingat agen juga merupakan perwakilan perusahaan juga karena bisa bertindak atas nama perusahaan salanjutnya biasanya disusul oleh pedagang biasa yang menjual tidak hanya menjual satu produk perusahaan. Di tingkat ini biasanya mudah sampai ke konsumen akhir tetapi ada juga yang disalurkan ke tingkat yang lebih kecil lagi seperti warung-warung yang kemudian bisa dipakai langsung oleh konsumen akhir. Selain perantara distribusi ada satu lagi perantara penting walaupum tidak melakukan penjualan langsung namun punya andil dalam menyampaikan barang ke konsumen yaitu fasilitator seperti agen iklan, distributor, bank dan lain-lain. Penelitian ini bertujuan untuk mengetahui proses produksi Kopi Arabika Gayo di CV. Gayo Mandiri Coffee dan saluran pemasaran Kopi Arabika Gayo di CV. Gayo Mandiri Coffee.

\section{METODOLOGI PENELITIAN}

Penelitian ini dilakukan pada CV. Gayo Mandiri Coffee di Desa Makmur Sentosa (Pondok Gajah), Kecamatan Bandar, Kabupaten Bener Meriah. Adapun metode pengumpulan data yang dilakukan metode observasi, yang merupakan salah satu metode pengumpulan data dengan cara melakukan pengamatan secara langsung yang meliputi kegiatan pemusatan perhatian terhadap suatu objek dengan menggunakan panca indera. Dalam hal ini mendatangi langsung dan melihat peroses produksi dan pemasaran di CV. Gayo Mandiri Coffee selama praktek kerja lapang berlangsung. Metode wawancara 
dilakukan melalui kegiatan wawancara dengan pimpinan/karyawan dari CV. Gayo Mandiri Coffee dengan mengajukan beberapa pertanyaan yang telah disiapkan sebelumnya. Analisis data dilakukan dengan metode deskriptif kualitatif.

Data yang digunakan dalam penelitian ini adalah data primer dan data skunder. Data primer didapatkan melalui pengamatan langsung dan ikut dalam kegiatan produksi serta wawancara dengan pimpinan/pekerja CV. Gayo Mandiri Coffee. Sedangkan data sekunder diperoleh dari berbagai sumber referensi yang berhubungan dengan penelitian yang dilakukan. Adapun data yang didapatkan seperti dari jurnal, buku, dan dari berbagai sumber referensi yang berhubungan dengan penelitian ini.

\section{HASIL DAN PEMBAHASAN}

CV. Gayo Mandiri Coffe adalah salah satu pengekspor Kopi Arabika Gayo yang merupakan anak perusahaan dari Koperasi Gayo Mandiri yang berdiri sejak tahun 2008 yang terletak di Desa Makmur Sentosa (Pondok Gajah), Kec.Bandar, Kab.Bener Meriah, AcehIndonesia. Memulai usaha dikarenakan adanya wacana program sertifikasi dan kebutuhan dari petani sehingga munculah wacana untuk mendirikan Koperasi dan selanjutnya dibuatlah badan hukumnya sehingga dapat berdirinya koperasi tersebut. Dari segi operasional Koperasi Gayo Mandiri terdiri dari pimpinan (manajer) dan juga staf karyawan. Dari segi kegiatan produksi di Koperasi Gayo Mandiri mereka mendapatkan bahan baku dari petani serta petani/kolektor juga dapat dapat melakukan kegiatan produksi mereka sendiri Dikoperasi Gayo Mandiri dan memasarkan melalui CV.Gayo Mandiri Coffee, adapun kegiatan produksi seperti penjemuran gabah kopi di areal koperasi di kenakan biaya dengan membayar upah kerja kepada CV.Gayo Mandiri Coffe. Pada umumnya petani yang memproduksi bahan baku berada di desa Silih Nara Kec.Pintu Rime Gayo dan petani di sekitar koperasi.

CV.Gayo Mandiri Coffee merupakan eksportir Kopi Arabika Gayo yang berupa green bean yang di dapatkan dari kolektor dan juga dari petani yang ada di sekitar koperasi. dalam peroses pemasaran jumlah yang diekspor tergantung dari permintaan dari luar negeri. Negara yang menjadi pasar utama ekspor kopi Arabika Gayo adalah Amerika dan juga beberapa negara di Eropa serta Asia. Dalam mengekspor green bean kemasan yang digunakan yaitu goni standar ekspor yang mempunyai kapasitas berat 60 $\mathrm{Kg} /$ goni sesuai dengan standar yang telah ditetapkan. Untuk menjaga kualitas kopi Arabika Gayo sebelum melakukan pengiriman maka dilakukan kembali pengecekan di pelabuhan Belawan,Sumatera Utara untuk memastikan kualitas kopi tidak mengalami kerusakan. Dalam proses pengangkutan green bean tersebut menggunakan mobil kontainer dari desa Makmur Sentosa sampai ke Belawan. Pada umumnya kopi yang diekspor diolah menjadi berbagai macam makanan dan minuman.

CV. Gayo Mandiri Coffe sudah mempunyai daftar negara tujuan, namun jumlah produksi yang dikirimkan tergantung dari permintaan. Sedangkan dalam proses produksi alat dan tempat 
sendiri tergantung dari kegiatan yang dilakukan. Adapun Kegiatannya seperti penjemuran gabah dan green mempunyai tempat berbeda, dimana gabah dijemur langsung pada halaman dan terkena terik matahari langsung sedangkan green bean dijemur pada kondisi ruang (canopy) dan juga di lengkapi dengan CCTV (kamera pengawas) untuk menjaga kualitas kopi dan juga keamanan. green bean yang sudah kering nantinya dikemas kedalam goni dengan dengan jumlah yang diminta negara importir dan selanjutnya barangakan dikirim ke pelabuhan Belawan, Sumatera Utara untuk selanjutnya dikirim ke negara tujuan ekspor. Begitu luasnya negara tujuan pangsa pasar kopi dan begitu menjanjikannya pasar kopi Arabika Gayo untuk dilakukan dan dikembangkan sehingga dapat

62 meningkatkan kesejahteraan pengusaha dan petani kopi. Berikut gambar proses produksi kopi.

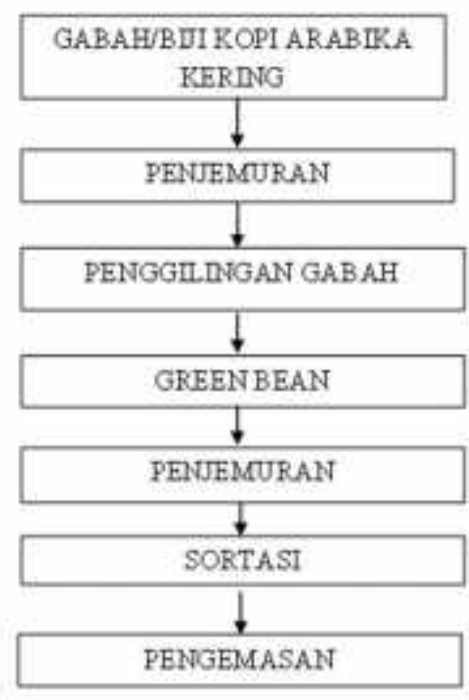

Gambar 1. Skema proses produksi kopi Arabika Gayo Di CV.Gayo Mandiri Coffee
Pemasaran kopi Arabika Gayo di CV.Gayo Mandiri Coffee telah memasarkan produknya keluar negeri seperti Amerika,Eropa (Jerman, Inggris, Belanda), Asia (Korea, Kamboja, China, Arab Saudi) dan negara lainnya. Dari masing- masing negara di Asia dalam setahun dua kali proses pengiriman tergantung dari permintaan. Adapun jumlah ekspor dalam sekali pengiriman yaitu 19 ton dengan harga Rp.65.000 - 70.000 per kg tergantung dengan nilai Rupiah. Dalam lingkungan Koperasi Gayo Mandiri ini juga mempunyai kafe tersendiri dalam memasarkan produknya yang berupa minuman kopi. Adapun Kemasan yang digunakan dalam mengekspor yaitu goni disertai dengan identitas perusahaan pengekspor dan selanjutnya barang tersebut dikirim ke negara tujuan. Pada pengiriman barang terlebih dahulu mempersiapkan dokumen untuk pembayaran. Dari berbagai negara sebagian melakukan pembayaran setengah harga terlebih dahulu sisanya setelah barang sampai dinegara tujuan ekspor dan sebagian bayar langsung lunas sekaligus adapun pembayarannya dalam bentuk dollar Amerika Serikat. Selain itu juaga Demi meningkatkan kualitas dan harag jual kopi Arabika Gayo CV.Gayo Mandiri sudah ikut dan mendapatkan berbagai sertifikasi internasional. Dari berbagai sertifikasi yang didapatkan Koperasi/CV. Gayo Mandiri Coffee seperti Rain Forest, Fair Trade, Usda, Jas dan lainnya.

Untuk gabah dibeli oleh CV.Gayo Mandiri Coffee dari petani dengan harga Rp.28.000-30.000/Kg dan melakukan pengolahan terhadap gabah tersebut menjadi green bean dan selanjutnya dilakukan proses 
penjemuran sampai kering seperti yang diinginkan dan selanjutnya dalam pemasaran produknya berupa green bean grade 1 dengan harga Rp.60.00065.000 atau bahkan lebih tergantung dari nialai tukar Rupiah. Pemasaran Kopi Arabika di CV. Gayo Mandiri Coffee juga dipasarkan dengan mempromosikan produknya kepada konsumen dengan menggunakan media sosial dan mengikuti bazaar didalam dan luar negeri.

Saluran pemasaran kopi terbagi menjadi dua saluran. Saluran I menjelaskan bahwa CV. Gayo Mandiri Coffe langsung menjual produknya kepada konsumen dengan harga $\mathrm{Rp}$ 60.000-65.000 tergantung dari nilai tukar Rupiah. saluran ini bisa dilihat langsung dari pemasaran yang menjual langsung produknya kepada konsumen diluar negeri. Saluran ini merupakan saluran yang paling dominan dikarenakan CV.Gayo Mandiri Coffee dalam memasarkan produknya langsung ke konsumen diluar negeri karena lebih memudahkan dalam transaksi.

Saluran II menjelaskan bahwa CV.Gayo Mandiri Coffee menjual produknya kepada pengecer (eksportir) Rp.60.000-65.000 dan selanjutnya eksportir memasarkan produknya kepada broker/perantara dan broker selanjutnya dipasarkan kepada konsumen(importir) dengan kisaran harga Rp.65.00-70.000. Adapun masing-masing negara yang mengimpor produk green bean seperti negaranegara di Asia, pada umumnya dalam proses pengiriman setahun dua kali pengiriman tergantung dari permintaan dan ketersediaan barang yang ada. Berbeda dengan negara Amerika Serikat karena mereka merupakan tujuan utama ekspor kopi Arabika Gayo. Adapun jumlah ekspor dalam sekali pengiriman yaitu 19 ton $(19.000 \mathrm{~kg})$ dengan harga $\$ 5$ per $\mathrm{kg}$ green bean tergantung dari ketersediaan barang, hal ini disebabkan tanaman tidak setiap waktu berproduksi karena tanaman kopi mempunyai musim-musim tertentu untuk bisa di panen dan setiap wilayah tidak lah sama waktunya dalam pemanenan buah kopi. Adapun kemasan yang digunakan dalam mengekspor yaitu goni disertai dengan identitas perusahaan pengekspor dan selanjutnya barang tersebut dikirim sesuai dengan negara tujuan.

\section{KESIMPULAN}

Pemasaran kopi Arabika Gayo di CV.Gayo Mandiri Coffee dalam memasarkan produknya terdapat dua saluran yaitu dari kolektor ke produsen sampai kepada konsumen, dari produsen langsung ke konsumen dan dari produsen ke pengecer serta melalui perantara kemudian sampai ketangan konsumen. Pemasaran kopi ini juga sudah sampai ke luar negeri seperti Amerika Serikat, Eropa (Jerman, Inggris, Belanda) Dan Asia (Korea, Kamboja, China, Arab Saudi).

\section{DAFTAR PUSTAKA}

Ahyari. 2002. Proses Produksi. Jakarta: Sinar Harapan.

Irawan, Swastha. 2005. Manajemen Pemasaran Modern. Yogyakarta: Liberty.

Kotler, Philip.1996. Manajemen Pemasaran Di Indonesia: Analisis, Perencanaan, Implementasi dan Pengendalian. Jakarta: Salemba Empat. 
2001. Dasar-Dasar

Pemasaran. Jilid.1. Jakarta:

Prenhallindo.

. 2000. "Analisis Marketing

Mix ( Product , Price ,

Promotion dan Place) yang

Mempengaruhi Kepuasan

Pelanggan Pengguna Operator ESIA" (Studi Kasus Pada Masyarakat Ciputat Timur ). Manajemen Pemasaran, 1-131.
Najiyati. 2004. Kopi Budidaya Dan Penanganan Pasca Panen. Jakarta: Penebar Swadaya.

Rahardjo, Pudji. 2012. Panduan Budidaya Dan Pengolahan Kopi Arabika Dan Robusta. Jakarta: Penebar Swadaya.

Stanton. 2001. Prinsip Pemasaran. Jakarta: Erlangga.

Swastha, Basu. 1996. Manajemen Pemasaran,Ed 3. Yogyakarta: BPFE. 